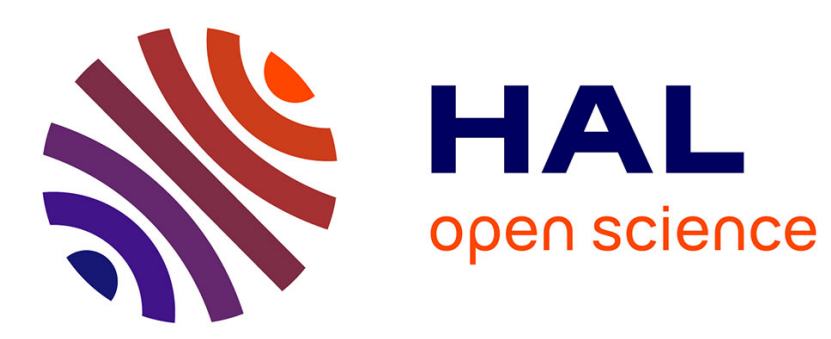

\title{
Model-free based water level control for hydroelectric power plants
}

\author{
Cédric Join, Gérard Robert, Michel Fliess
}

\section{To cite this version:}

Cédric Join, Gérard Robert, Michel Fliess. Model-free based water level control for hydroelectric power plants. IFAC Conference on Control Methodologies and Tecnologies for Energy Efficiency, CMTEE, IFAC, 2010, Vilamoura, Portugal. pp.CDROM. inria-00458042

\section{HAL Id: inria-00458042 \\ https://hal.inria.fr/inria-00458042}

Submitted on 19 Feb 2010

HAL is a multi-disciplinary open access archive for the deposit and dissemination of scientific research documents, whether they are published or not. The documents may come from teaching and research institutions in France or abroad, or from public or private research centers.
L'archive ouverte pluridisciplinaire HAL, est destinée au dépôt et à la diffusion de documents scientifiques de niveau recherche, publiés ou non, émanant des établissements d'enseignement et de recherche français ou étrangers, des laboratoires publics ou privés. 


\title{
Model-Free Based Water Level Control for Hydroelectric Power Plants
}

\author{
Cédric JOIN* Gérard ROBERT ${ }^{* *}$ Michel FLIESS ${ }^{* * *}$ \\ * INRIA-ALIEN \&ु CRAN (UMR CNRS 7039) \\ Nancy-Université, BP 239, 54506 Vandœuvre-lès-Nancy, France \\ (e-mail: Cedric.Join@cran.uhp-nancy.fr) \\ ** EDF, Centre d'Ingénierie Hydraulique \\ Savoie Technolac, 73373 Le Bourget du Lac, France \\ (e-mail: gerard.robert@edf.fr) \\ *** INRIA-ALIEN \&3 LIX (UMR CNRS 7161) \\ École polytechnique, 91128 Palaiseau, France \\ (e-mail: Michel.Fliess@polytechnique.edu)
}

\begin{abstract}
Automatic water level control methods for open channels have difficulties to keep good performances for a large range of flow and significant unknown disturbances. A new concept called Model-Free Control is applied in this paper for hydroelectric run-of-the river power plants. To modulate power generation, a level trajectory is planned for cascaded power plants. Numerous dynamic simulations show that with a simple and robust control algorithm, the set-point is followed even in severe operating conditions.
\end{abstract}

Keywords: Hydroelectric power plants, channels, water level, model-free control, intelligent PI controllers, numerical differentiation of noisy signals.

\section{INTRODUCTION}

Automatic water level control in open channels remains a challenge for researchers and engineers, as demonstrated by an abundant literature (see, e.g., Cantoni, Weyer, Li, Ooi, Mareels \& Ryan (2007); Dang Van Mien (1999); Dumur, Libaux \& Boucher (2001); Georges \& Litrico (2002); de Halleux, Prieur, Coron, d'Andréa-Novel, Bastin, (2003); Litrico \& Fromion (2009); Rabbani, Dorchies, Malaterre, Bayen \& Litrico (2009); Thomassin, Bastogne \& Richard (2009); Zhuan \& Xia (2007)). The excellent review by Zhuan \& Xia (2007), which is devoted to channel flow control methodologies, insists on the inherent complexity of this type of problems. The difficulties are explained by the features of the process to control:

- non-uniform long canal (tens of kilometers) with variable roughness,

- slow water flow dynamics described by two coupled nonlinear partial differential equations (Saint-Venant equations), where the unknown functions are time and space dependent,

- multivariable nonlinear finite-dimensional system,

- important unknown disturbances, which are due to seasonal fluctuations, natural inflows or outflows, agricultural withdrawals and lock opening for navigation.

According to Zhuan \& Xia (2007)) the two most popular control techniques for industrial channel control are op-

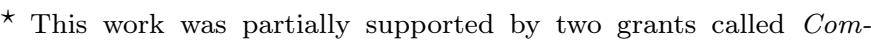
mande sans modèle pour aménagements hydroélectriques en cascade between EDF on one hand, and the École polytechnique, INRIA, and CNRS on the other hand. timal control and PI control. The PI control is often a feedforward PI control in order to anticipate with known inflows. However, feedforward action alone may not be enough to guarantee good performances for all operating flow conditions. That's why gain-scheduling PI controllers with a feedforward term are often necessary in order to cope with nonlinearities.

Water level control applications in open channels do not only concern irrigation but also electricity generation by Hydroelectric Power Plants. As a power producer, EDF (Électricité de France) uses water resources to generate green electricity in France (239 dams, 447 hydropower stations with 20300 MW of installed capacity, including $4500 \mathrm{MW}$ in pumped-storage) and in international projects. A water level control system is implemented in the SCADA of every run-of-the-river power plant. These cascaded hydroelectric plants transfer water flow from upstream to downstream without spillage and convert the flow into electric energy through hydraulic turbines. A runof-the-river power plant has very little capacity for energy storage, but a small energy reserve can be realized by controlling the level trajectory in the canal separating two power stations. This principle is used by EDF to modulate power generation according to electricity demand and in order to optimize the whole production taking into account nuclear and thermal generation scheduling.

The water level control with river power plant constitutes a level set-point following problem with rejection of flow disturbances with nonlinear dynamics. This paper presents an investigation concerning a new concept of water level control, i.e., Model-Free Control (Fliess \& Join (2008, 2009)), applied to a channel power plant described in 
Section 3. We do not need with this viewpoint any precise mathematical modeling of the process. ${ }^{1}$

\section{MODEL-FREE CONTROL: A BRIEF OVERVIEW}

\subsection{General principles}

We only assume that the plant behavior is well approximated in its operational range by a system of ordinary differential equations, which might be highly nonlinear and time-varying. ${ }^{2}$ Our system, which is SISO, may be therefore described by the input-output equation

$$
E\left(t, y, \dot{y}, \ldots, y^{(\iota)}, u, \dot{u}, \ldots, u^{(\kappa)}\right)=0
$$

where

- $u$ and $y$ are the input and output variables,

- $E$, which might be unknown, is assumed to be a sufficiently smooth function of its arguments.

Assume that for some integer $n, 0<n \leq \iota, \frac{\partial E}{\partial y^{(n)}} \not \equiv 0$. The implicit function theorem yields then locally

$y^{(n)}=\mathfrak{E}\left(t, y, \dot{y}, \ldots, y^{(n-1)}, y^{(n+1)}, \ldots, y^{(\iota)}, u, \dot{u}, \ldots, u^{(\kappa)}\right)$

This equation becomes by setting $\mathfrak{E}=F+\beta u$ :

$$
y^{(n)}=F+\beta u
$$

where

- $\beta \in \mathbb{R}$ is a non-physical constant parameter, such that $F$ and $\beta u$ are of the same magnitude;

- the numerical value of $F$, which contains the whole "structural information", is determined thanks to the knowledge of $u, \beta$, and of the estimate of the derivative $y^{(n)}$.

In all the numerous known examples it was possible to set $n=1$ or 2 .

\subsection{Intelligent PI controllers}

If $n=1$, we close the loop via the intelligent PI controller, or $i$-PI controller,

$$
u=-\frac{F}{\beta}+\frac{\ddot{y}^{*}}{\beta}+K_{P} e+K_{I} \int e
$$

where

- $y^{*}$ is the output reference trajectory, which is determined via the rules of flatness-based control;

- $e=y-y^{*}$ is the tracking error;

- $K_{P}, K_{I}$ are the usual tuning gains.

Remark 1. The i-PI controller (2) is compensating the poorly known term $F$. Controlling our system boils therefore down to the control of a precise and elementary pure integrator. The tuning of the gains $K_{P}$ and $K_{I}$ becomes therefore quite straightforward. ${ }^{3}$

\footnotetext{
${ }^{1}$ Let us emphasize that Model-Free Control has already been most successfully applied in several quite different areas. See Choi, d'Andréa-Novel, Fliess, Mounier \& Villagra (2009); Gédouin, Join, Delaleau, Bourgeot, Chirani \& Calloch (2008); Join, Masse \& Fliess (2008); Villagra, d'Andréa-Novel, Choi, Fliess \& Mounier (2010).

2 See Fliess \& Join $(2008,2009)$ for further details.

3 Compare with PI controllers in today's literature (see, e.g., Åström \& Hägglund (2006); O'Dwyer (2006)).
}

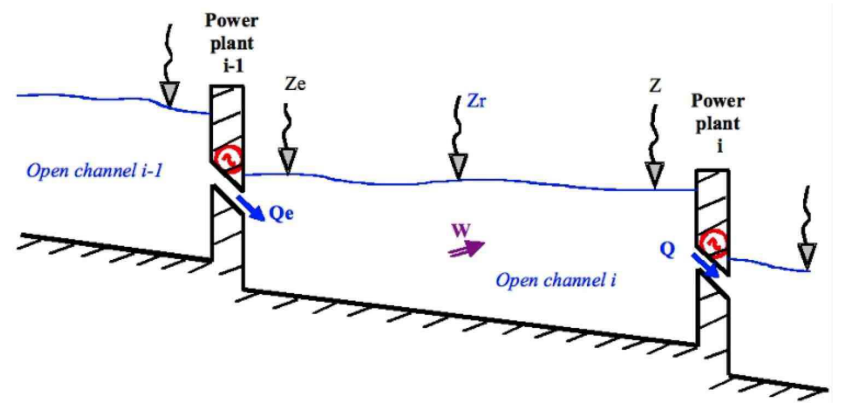

Figure 1. Canal scheme

\subsection{Numerical derivation of noisy signals}

Numerical derivation, which is a classic field of investigation in engineering and in applied mathematics, is a key ingredient for implementing the feedback loop (1). Our solution has already played an important role in model-based nonlinear control and in signal processing (see Fliess, Join \& Sira-Ramírez (2008) for further details and related references). Important theoretical developments, which are of utmost importance for the computer implementation, may be found in Mboup, Join \& Fliess (2009).

The estimate of the $1^{\text {st }}$ order derivative of a noisy signal $y$ reads (see, e.g., García Collado, d'Andréa-Novel, Fliess, \& Mounier (2009))

$$
\hat{\dot{y}}=-\frac{3 !}{T^{3}} \int_{0}^{T}(T-2 t) y(t) d t
$$

where $[0, T]$ is a quite "short" time window. 4 This window is sliding in order to get this estimate at each time instant.

Denoising of $y$ leads to the estimate

$$
\hat{y}=\frac{2 !}{T^{2}} \int_{0}^{T}(2 T-3 t) y(t) d t
$$

\section{THE CANAL}

\subsection{General description}

The open channel considered is $15 \mathrm{~km}$ long and located at Fessenheim in the Grand Canal d'Alsace derived from the Rhine River in the east of France. The Rhine River French-German portion includes ten cascaded river power plants built from 1932 to 1977 and offering a total power capacity of $1400 \mathrm{MW}$. Those plants are controlled through a centralized remote control system. Fessenheim's channel is fed by the upstream power station $i-1$ and ended by the Fessenheim power station $i$ which controls the water levels $Z_{e}, Z_{r}$, and $Z$ (see Figure 1 ).

To limit the impact of hydro facilities on the water level and on the flow, authorities impose operating constraints mainly linked to navigation conditions: water levels must follow the set-point with a tolerance of $\pm 10 \mathrm{~cm}$ and discharge variations must verify:

$$
\begin{gathered}
0 \leq Q \leq 1400 \mathrm{~m}^{3} / \mathrm{s} \\
-20 \leq \frac{d Q}{d t} \leq 20 \mathrm{~m}^{3} / \mathrm{s} / \mathrm{min}
\end{gathered}
$$

In normal conditions, the objective of the water level controller is to maintain the level $Z_{r}$, which is as far as 7.5

\footnotetext{
4 It implies in other words that we obtain real-time techniques.
} 


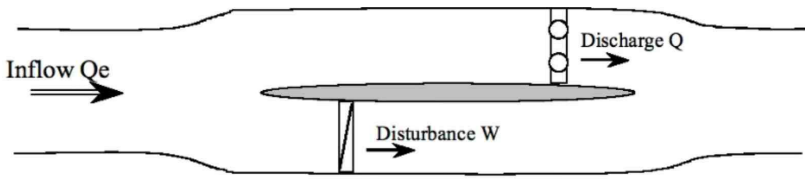

Figure 2. Navigation disturbances

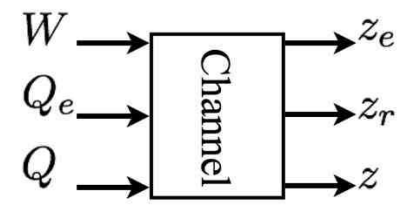

Figure 3. Block diagram of the system

$\mathrm{km}$ from the actuator, as close as possible to its set-point. In poor conditions, a loss of $Z_{e}, Z_{r}$ water level capture may be encountered and the controller must be able to control the remaining level $Z$ located next to the actuator. We focus here in this particular case where the task of the controller will be to control the level $Z$ with respect to its variable set-point and significant flow disturbances $W$ due to handling of lock for the navigation (see Fig. 2).

The system is disturbed by two exogenous inputs (see Fig. $3)$ :

(1) the inflow $Q_{e}$,

(2) the disturbance $W$.

The control variable $u$ is sampled and saturated with respect to its position and its speed. Associate to the Model-Free Control an additional feedforward term, which is connected to the measurement of the channel inflow. Figure 4 displays the control scheme.

\subsection{Control synthesis}

Closing the loop For the design of the Model-Free Control, rewrite Eq. (1) in the following way

$$
\alpha \dot{y}=F-u
$$

where $\alpha$ is a suitable numerical constant. The physical interpretation of $F$ becomes then straightforward.

The estimation of $F$ follows from

$$
[F]_{e}=\alpha[\dot{y}]_{e}+u
$$

where $[\dot{y}]_{e}$ is the estimated value of the derivative of the measure $y$. The i-PI controller (2) is selected in such a way that the polynomial $s^{2}+K_{P} s+K_{I}$ possesses a double negative root $p_{c d e}$. Then

$$
K_{p}=-2 p_{c d e} \quad K_{i}=p_{c d e}^{2}
$$

We have chosen after a few attempts

$$
p_{c d e}=-10^{-4}
$$

The feedforward term The feedforward term displayed in Fig. 4 is connected to the input flow $Q e$, which is measured and allows to forecast the evolution of the water height in the reach. The influence of the flow is of course not immediate. The corresponding delay $\tau$ depends on the geometry of the reach. After a few attempts we set $\tau=2 T_{e}$, where $T_{e}=300 \mathrm{~s}$ is defined in Table 1 . In order to attenuate the influence of the quick fluctuations of $Q e$, a low pass filter is added. Its time constant $T$ should not

\begin{tabular}{|l|c|l|}
\hline Simulation parameters & Units & Values \\
\hline \hline Sample time $T_{e}$ & $s$ & 300 \\
Channel length & $m$ & 14080 \\
Channel surface $A$ & $\mathrm{~m}^{2}$ & $2.57 .10^{6}$ \\
Minimal set-point $z_{\min }^{*}$ & $m$ & 214.5 \\
Maximal set-point $z_{\max }^{*}$ & $m$ & 215.1 \\
Sensor sensibility & $\mathrm{cm}$ & 1 \\
\hline
\end{tabular}

Table 1 .

be too large in order to avoid adding another important delay. We set $T=2 T_{e}$.

\section{SIMULATION RESULTS}

\subsection{Two types of lock discharges}

Frequent lock discharges As shown in Figures 5, 6, 7, the desired constraints are not respected.

Less frequent lock discharges The results displayed by Figures 8, 9, 10 are quite excellent. The desired constraints are respected with the only exception of the extreme scenario 1.

Anti-windup Figures 7 and 10 show the efficiency of our anti-windup strategy: the control variable is immediately decreasing when the inflow is decreasing.

A comment on the feedforward term Figures 11 and 12 display the behavior without the feedforward term in the simplest case: its quality is much lower than in Figures 8 and 9 , where the feedforward term is utilized.

\section{CONCLUSION}

Our Model-Free Control has allowed the design of a new water level controller, which is able to insure good trajectory tracking performance even in severe operating conditions (lock discharges close to the level sensor). The advantages of this control method are appreciable for industrial applications because:

- a mathematical model of the process is no more necessary, and therefore complex identification procedures are bypassed;

- there are only three control parameters, which are easy to tune;

- the performances are robust for a large range of operating points.

It implies, from a practical point of view, a time reduction of commissioning tests and an easier maintenance.

Model-free based water level control strategy can be applied for any Hydroelectric Power Plants (run-of-the river power plants but also reservoir power plants) and for irrigation issues. An extended control structure has also been developed to control the distant level $Z_{r}$ (see Join, Robert \& Fliess (2010)).

\section{REFERENCES}

K.J. Åström, T. Hägglund, Advanced PID Control, Instrument Soc. Amer., 2006. 


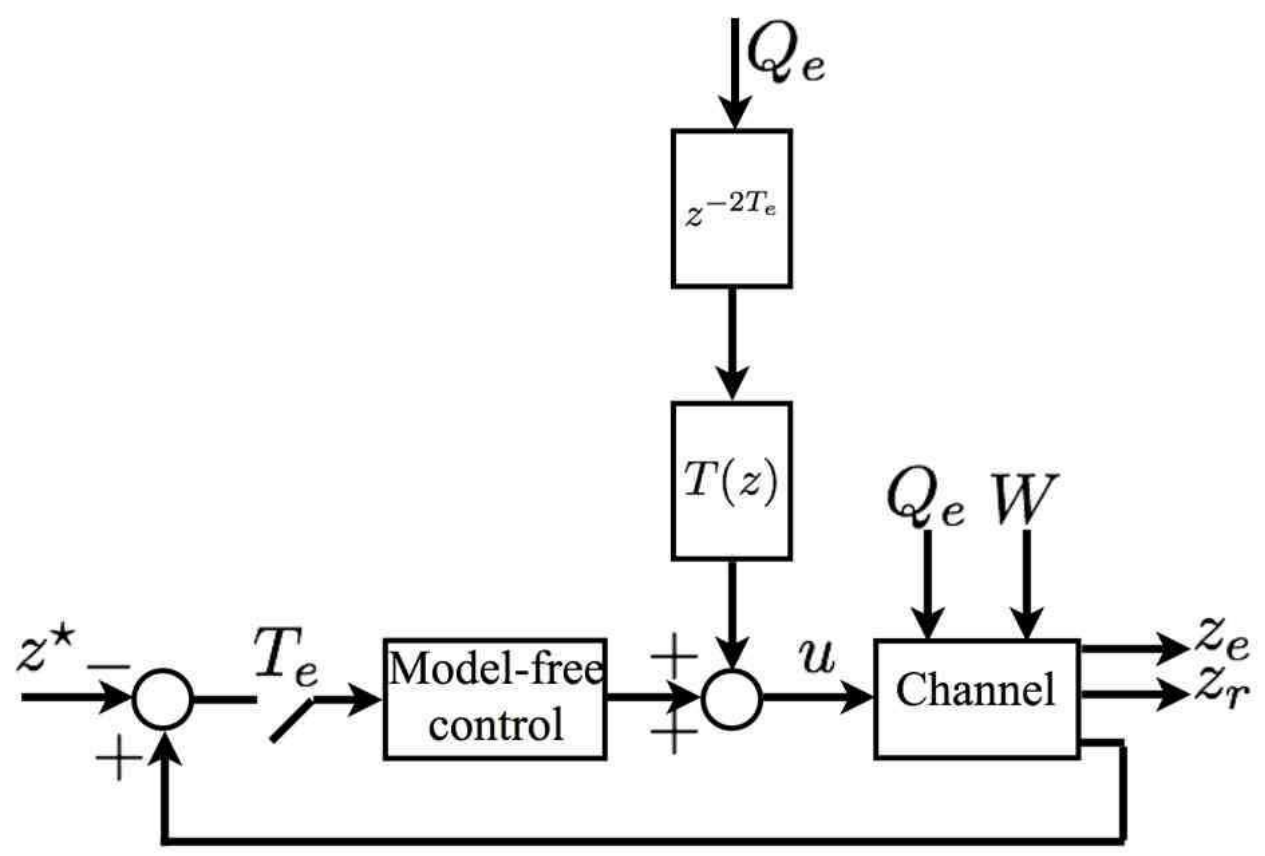

Figure 4. Block diagram for the desired control law

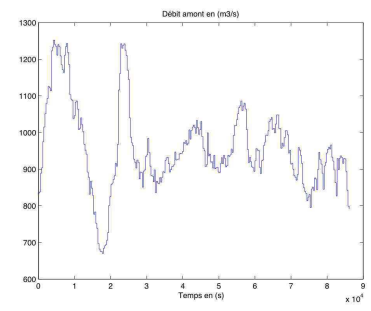

(a) Upstream flow

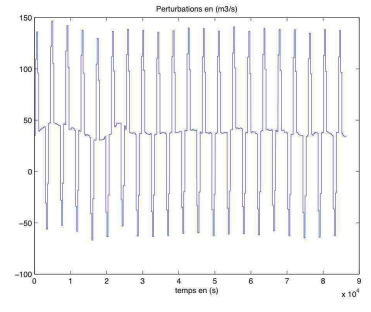

(b) Perturbations: bias and lock discharges

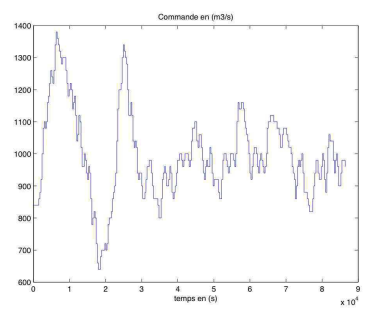

(c) Control variable

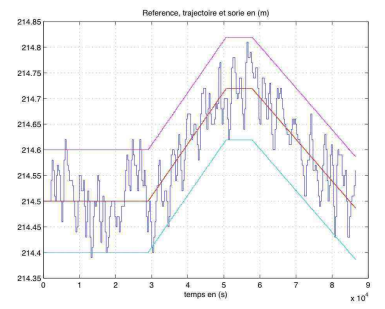

(d) Output variable

Figure 5. $1^{\text {st }}$ scenario and frequent lock discharges

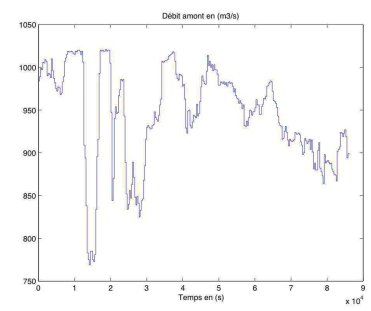

(a) Upstream flow

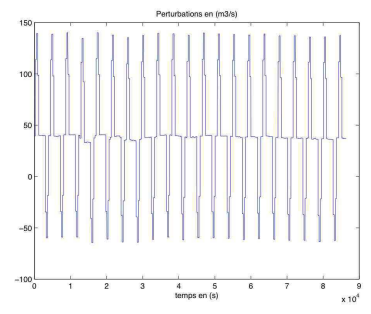

(b) Perturbations: bias and lock discharges

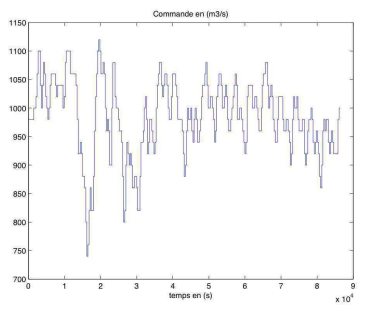

(c) Control variable

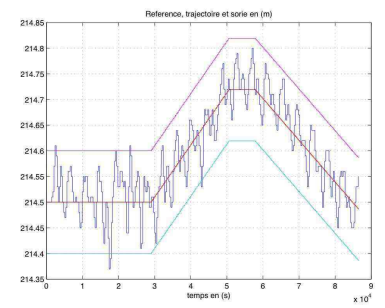

(d) Output variable

Figure 6. $2^{\text {nd }}$ scenario and frequent lock discharges 


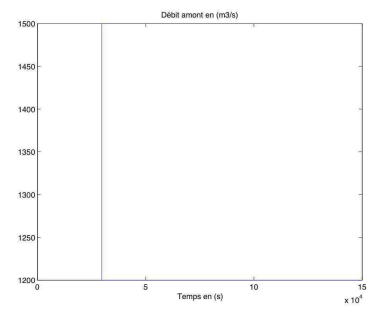

(a) Upstream flow

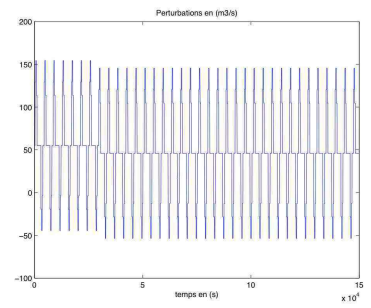

(b) Perturbations: bias and lock discharges

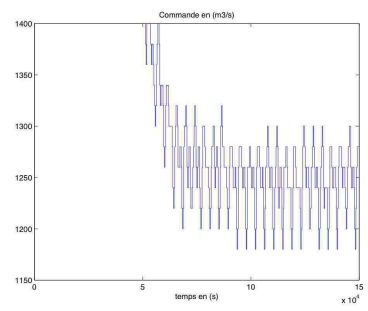

(c) Control variable

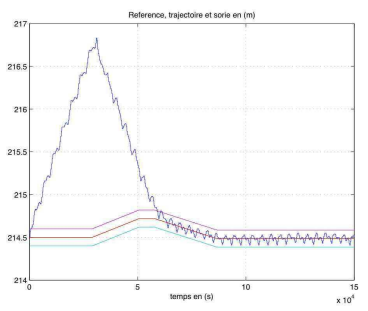

(d) Output variable
Figure 7. $3^{\text {rd }}$ scenario and frequent lock discharges

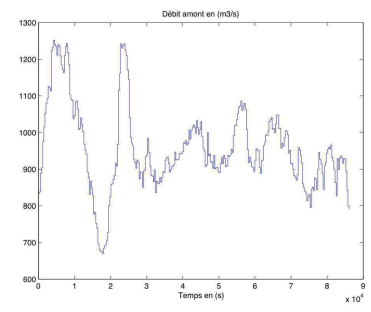

(a) Upstream flow

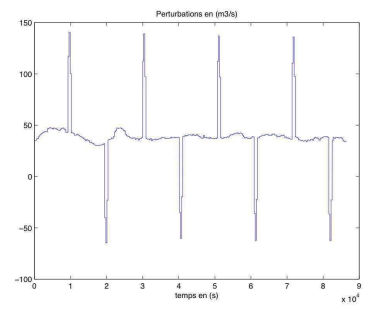

(b) Perturbations: bias and lock discharges
Figure 8. $1^{\text {st }}$ scenario and less frequent lock discharges

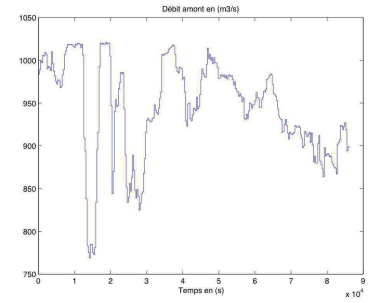

(a) Upstream flow

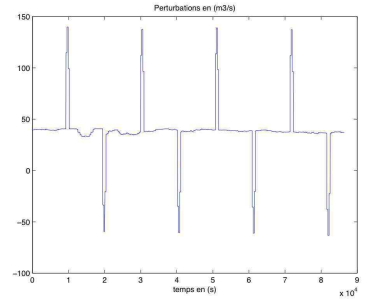

(b) Perturbations: bias and lock discharges

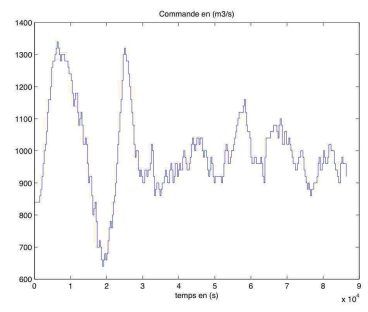

(c) Control variable

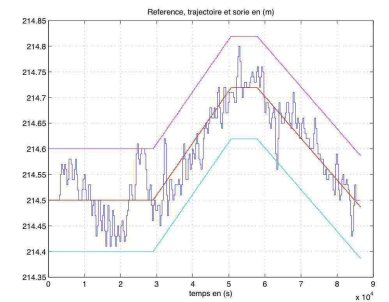

(d) Output variable

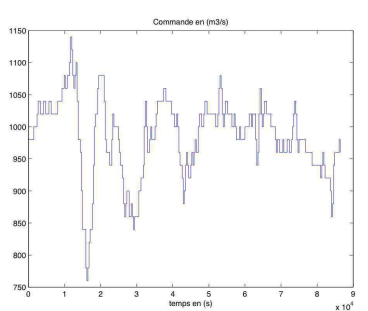

(c) Control variable

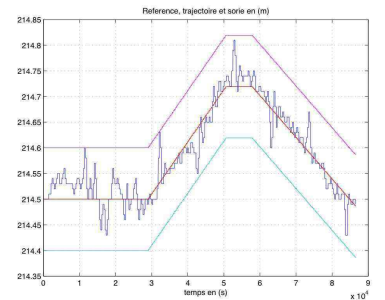

(d) Output
Figure 9. $2^{\text {nd }}$ scenario and less frequent lock discharges

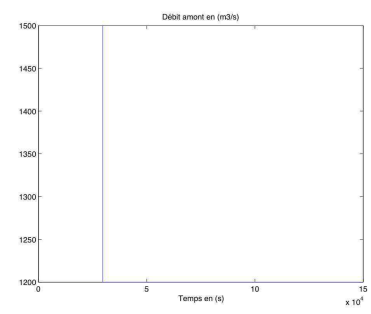

(a) Upstream flow

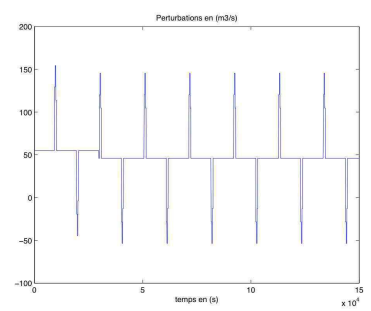

(b) Perturbations: bias and lock discharges
Figure 10. $3^{r d}$ scenario and less frequent lock discharges

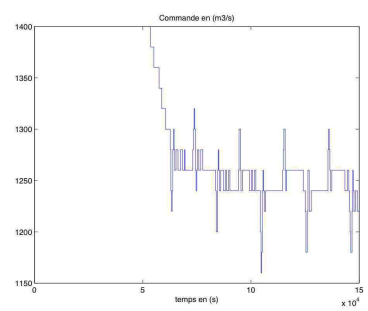

(c) Control variable

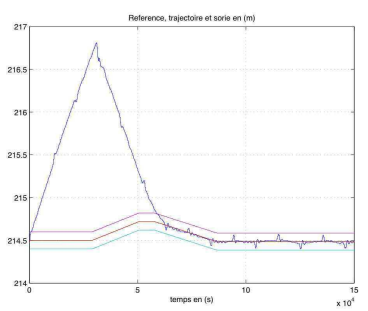

(d) Output variable 


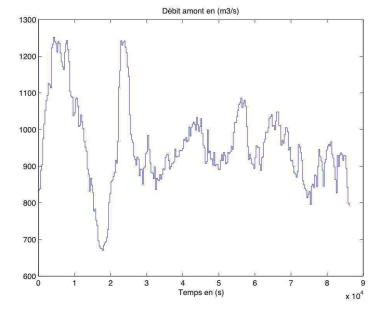

(a) Upstream flow

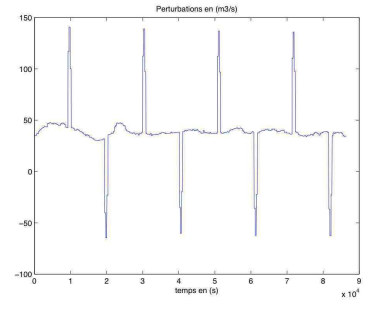

(b) Perturbations: bias and lock discharges

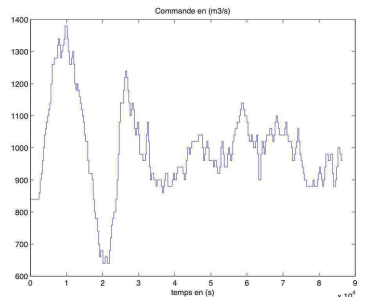

(c) Control variable

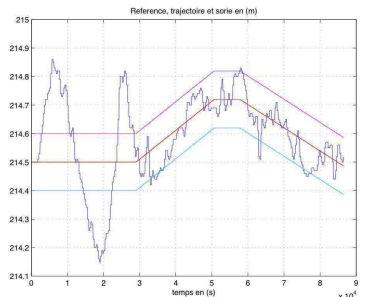

(d) Output variable

Figure 11. $1^{\text {st }}$ scenario without feedforward and less frequent lock discharges

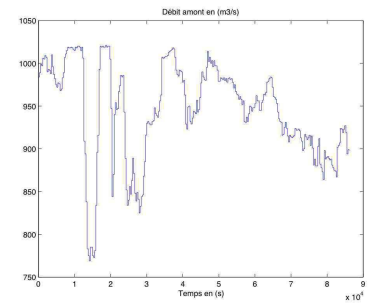

(a) Upstream flow

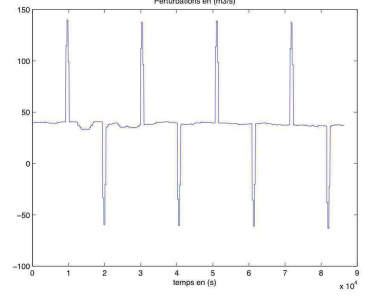

(b) Perturbations: bias and lock discharges

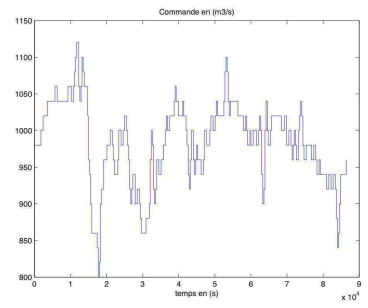

(c) Control variable

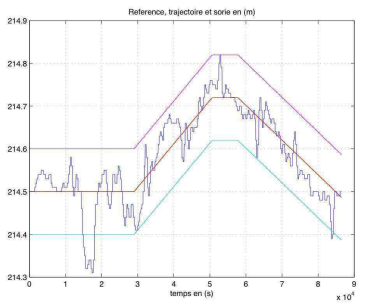

(d) Output variable

Figure 12. $2^{\text {nd }}$ scenario without feedforward and less frequent lock discharges

M. Cantoni, E. Weyer, Y. Li, S.K. Ooi, I. Mareels, M. Ryan, Control of large-scale irrigation networks, Proc. IEEE, vol. 95, pp. 75-91, 2007.

S. Choi, B. d'Andréa-Novel, M. Fliess, H. Mounier, J. Villagra, Model-free control of automotive engine and brake for Stop-and-Go scenarios, Europ. Control Conf., Budapest, 2009 (online http://hal.inria.fr/inria-00395393/en/).

H. Dang Van Mien, Automatisation des systèmes industriels, Eyrolles, 1999.

D. Dumur, A. Libaux, P. Boucher, Robust RST control for Basse-Isère run-of-river cascaded hydro-electric plants, IEEE Internat. Conf. Control Applications, Mexico City, 2001.

M. Fliess, C. Join, Commande sans modèle et commande à modèle restreint, e-STA, vol. 5 (n $\left.{ }^{\circ} 4\right)$, pp. 1-23, 2008 (online http://hal.inria.fr/inria-00288107/en/).

M. Fliess, C. Join, Model-free control and intelligent PID controllers: towards a possible trivialization of nonlinear control?, $15^{\text {th }}$ IFAC Symp. System Identif., Saint-Malo, 2009 (online http://hal.inria.fr/inria-00372325/en/).

M. Fliess, C. Join, H. Sira-Ramírez, Non-linear estimation is easy, Int. J. Modelling Identification Control, vol. 4, pp. 12-27, 2008 (online http://hal.inria.fr/inria-00158855/en/).

P.-A. Gédouin, C. Join, E. Delaleau, J.-M. Bourgeot, S.A. Chirani, S. Calloch, Model-free control of shape memory alloys antagonistic actuators, 17th IFAC World Congress, Seoul, 2008 (online http://hal.inria.fr/inria-00261891/en/).

F.A. García Collado, B. d'Andréa-Novel, M. Fliess, H. Mounier, Analyse fréquentielle des dérivateurs algébriques, XXII Coll. GRETSI, Dijon, 2009 (online http://hal.inria.fr/inria-00394972/en/).
D. Georges, X. Litrico, Automatique pour la gestion des ressources en eau, Hermès, 2002.

J. de Halleux, C. Prieur, J.-M. Coron, B. d'Andréa-Novel, G. Bastin, Boundary feedback control in networks of open channels, Automatica, vol. 39, pp. 1365-1376, 2003.

C. Join, J. Masse, M. Fliess, Étude préliminaire d'une commande sans modèle pour papillon de moteur, $J$. europ. syst. automat., vol. 42, pp. 337-354, 2008 (online http://hal.inria.fr/inria-00187327/en/).

C. Join, G. Robert, M. Fliess, Vers une commande sans modèle pour aménagements hydroélectriques en cascade, $6^{e}$ Conf. Internat. Francoph. Automatique, Nancy, 2010 (soon online http://hal.inria.fr/).

X. Litrico, V. Fromion, Modeling and Control of Hydrosystems, Springer, 2009.

M. Mboup, C. Join, M. Fliess, Numerical differentiation with annihiators in noisy environment, Numer. Algor., vol. 50, pp. 439-467, 2009.

A. O'Dwyer, Handbook of PI and PID Controller Tuning Rules, $2^{\text {nd }}$ ed., Imperial College Press, 2006.

T. Rabbani, S. Munier, D. Dorchies, P.-A. Malaterre, A. Bayen, X. Litrico, Flatness-based control of open channel flow in an irrigation canal using SCADA, IEEE Control Systems Magaz., vol. 29, pp. 22-30, 2009.

M. Thomassin, T. Bastogne, A. Richard, Identification of a managed river reach by a Bayesian approach, IEEE Trans. Control Systems Technology, vol. 17, p. 353-365, 2009.

J. Villagra, B. d'Andréa-Novel, S. Choi, M. Fliess, H. Mounier, Robust stop-and-go control strategy: an algebraic approach for nonlinear estimation and control, Int. J. Vehicle Autonomous Systems, 2010 (online http://hal.inria.fr/inria-00419445/en/).

X. Zhuan, X. Xia, Models and control methodologies in open water flow dynamics: A survey, IEEE Africon, Windhoek, Namibia, 2007. 